\title{
A caracterização da pobreza urbana ao longo do tempo: aplicação do modelo idade-período- coorte na estimação das tendências de privações crônica e transitória no Brasil ${ }^{\star}$
}

\author{
Rafael Perez Ribas ${ }^{\star \star}$
}

\begin{abstract}
Ao longo das últimas décadas, a pobreza no Brasil vem mudando seu perfil, devido, em parte, a alterações no padrão de reprodução e mortalidade da população. Da mesma forma, os desenhos de políticas sociais, especialmente de combate à pobreza, tomaram outros rumos. Nesse aspecto, a pertinência desses novos desenhos depende da natureza da condição de baixa renda, podendo ser entendida como um fenômeno permanente ou temporário e, principalmente, da tendência de mudanças nessa composição transitória-crônica (T-C). O objetivo deste trabalho é justamente analisar essa tendência, assim como o processo de incidência da pobreza urbana, em termos de mudanças ao longo do tempo e de gerações de indivíduos, projetando medidas futuras de privação na renda. Para tanto, é utilizado um modelo de idade-período-coorte (IPC) sobre a pobreza, absoluta e relativa, observada nas PNADs entre 1995 e 2003, e sobre sua composição T-C estimada. Os resultados apontam que o efeito coorte é mais expressivo do que o de período sobre a redução da pobreza recentemente, em especial de seu componente crônico. Já o componente transitório apresenta tendência de aumento ao longo do tempo.
\end{abstract}

Palavras-chave: Pobreza crônica e transitória. Modelo idade-período-coorte (IPC). Projeção de pobreza.

\section{Introdução}

O perfil da pobreza no Brasil passou por diversas mudanças nos últimos 30 anos (ROCHA, 2003). Parte dessa reconfiguração da população de baixa renda está relacionada a mudanças ocorridas na composição das famílias brasileiras nas últimas duas décadas, que, segundo Medeiros e Osório (2002), provêm da alteração nos padrões de reprodução, mortalidade e estado conjugal. Juntamente com essas mudanças, o desenho de políticas sociais no Brasil acaba seguindo novos rumos, principalmente nos últimos dez anos (ARBACHE, 2003).

Segundo Villalobos (2000), as políticas sociais necessariamente tornam-se mais complexas ao longo do tempo, sendo necessário adaptá-las e ajustá-las dentro da tarefa de modernização do Estado. O tratamento homogêneo e padronizado dos problemas sociais, sem atenção especial desde o diagnóstico, em relação ao grupo específico atingido ou à situação que se quer enfrentar, acaba por gerar crises na eficiência e eficá-

\footnotetext{
*Este artigo é derivado da Dissertação de Mestrado "Permanência, Transição, Vulnerabilidade? três análises dinâmicas sobre a pobreza no Brasil", orientado pela Professora Ana Flávia Machado. Agradeço os comentários de Ana Flávia Machado, André Braz Golgher, Ana Maria Hermeto Oliveira, Simone Wajnman, Sergei Soares e dos pareceristas anônimos. Apesar disso, permaneço como o único responsável por eventuais erros e omissões.

${ }^{* *}$ Pesquisador do Centro Internacional de Pobreza/UNDP e Cedeplar/UFMG.
} 
cia de programas. Nesse aspecto, segundo McKay e Lawson (2002), a distinção entre grupos de indivíduos cronicamente pobres e transitoriamente pobres implica políticas diferenciadas, mais apropriadas para cada caso. Gaiha e Deolalikar (1993) afirmam que medidas de mudança para corrigir falhas de mercado, como o de trabalho ou de crédito, podem ajudar a aliviar a pobreza transitória, porém não causam nenhum impacto sobre a pobreza persistente. Já as políticas de transferência de renda condicionadas à acumulação de capital humano podem amenizar a pobreza crônica, mas não garantem necessariamente uma situação de seguridade aos indivíduos.

O trabalho de Ribas e Machado (2007) identificou que, entre 1995 e 2003, quase três quartos da pobreza observada para indivíduos com idade entre 27 e 50 anos, em 1995, decorrem de um componente crônico. No entanto, apesar de traçar um perfil das pobrezas transitória e crônica, o retrato destes oito anos não ilustra com clareza o processo longitudinal dessa composição. Uma maneira de estimar essas tendências está em controlar três dimensões críticas deste tipo de análise: a idade do evento; o período de sua ocorrência; e a coorte dos indivíduos envolvidos.

Dessa forma, o objetivo deste trabalho é analisar a tendência de incidência da pobreza urbana e de suas procedências (estruturais ou transitórias), em termos de mudanças ao longo dos períodos e das gerações de indivíduos, dissociada da trajetória de ciclo de vida dessas pessoas. Com isso, pretende-se ainda projetar as medidas de privação, identificando o rumo de um dos problemas sociais brasileiro. Para cumprir esse objetivo, é utilizado um modelo de estimação de idade-período-coorte-IPC (GLENN, 1976; GOLDSTEIN, 1979; RODGERS, 1982), que possibilita isolar o efeito puro das três dimensões dentro de uma análise intertemporal, servindo também de base para técnicas de projeção da distribuição futura de determinado atributo na população. ${ }^{1}$
Cabe salientar que, para estimar o componente crônico da pobreza, consideraram-se determinantes as características inerentes aos indivíduos, tais como sexo, raça, escolaridade, região de residência e período de nascimento, além dos efeitos conjunturais. Essa escolha foi realizada por causa do método de estimação markoviano, com base num pseudopainel, e pela possibilidade de controlar a endogeneidade no processo de transição, com um melhor ajuste dos instrumentos (RIBAS; MACHADO, 2007). Por outro lado, o modelo IPC, aplicado sobre os componentes já estimados, é mais simples e sua estrutura objetiva unicamente investigar processos ao longo do tempo.

A fonte dos dados utilizada é a Pesquisa Nacional por Amostra de Domicílios (PNAD). Os microdados dessa pesquisa são organizados em forma de um painel empilhado para 1995, 1997, 1999, 2001 e 2003. A medida de pobreza adotada para cada indivíduo deriva da comparação entre sua renda familiar per capita e uma linha de pobreza, definida em termos de privações absoluta e relativa.

Este artigo divide-se em cinco partes, além dessa introdução. Na primeira, são especificados os modelos de decomposição transitória-crônica e de efeitos IPC sobre a pobreza. Na segunda, descreve-se a metodologia de estimação, apresentando fonte e tratamento das informações e técnicas econométricas utilizadas. Os resultados das regressões do modelo IPC são reportados na terceira parte e os das projeções encontram-se na seção seguinte. Por último, são traçadas algumas considerações finais com base nesses resultados.

\section{Especificação do modelo}

Uma maneira simples, porém precisa, de se analisar a pobreza ao longo de tempo é utilizar um modelo que integre os efeitos de idade, período e coorte de nascimento em uma mesma estrutura determinante do

\footnotetext{
${ }^{1}$ Como exemplo, Rios-Neto e Oliveira (1999) projetam as taxas de participação feminina e masculina na População Economicamente Ativa brasileira.
} 
processo. Além disso, a pobreza observada, em determinados períodos, pode provir de diferentes aspectos, em termos de sua persistência, ou condicionalidade, e de seu risco, ou transitoriedade. Segundo McKay e Lawson (2002), a pobreza crônica possui características e determinantes distintos de uma condição de privação transitória, não podendo ser tratadas de uma mesma maneira.

\section{Funções de pobrezas crônica e transitória}

O modelo de análise da pobreza em aspectos crônicos e transitórios é baseado na abordagem de componentes, proposta por Jalan e Ravallion (1998, 2000), que prioriza a deficiência de renda ao longo do tempo. A finalidade é distinguir o componente constante da renda, determinante da pobreza crônica, do componente de flutuação, determinante da pobreza transitória, assumindo a hipótese de renda permanente das famílias (ou indivíduos). Partindo do modelo original de Ravallion (1988) e Jalan e Ravallion (1998, 2000), Ribas e Machado (2007) propõem uma decomposição semelhante sobre a propensão individual à pobreza, com base na transição de estados entre dois períodos.

Supondo que $\varphi($.) é uma função de transformação das características inerentes ao indivíduo $j, x_{j}$, constante no tempo, e de sua renda no período anterior, $y_{j d-1}$, em uma renda individual permanente e que a variável aleatória $\eta_{d}$, comum a todos, transformada pela função idiossincrática $v_{j}($. determina os desvios dessa renda ao longo do tempo, a renda total do indivíduo $j$, no período $d, y_{j d}$, é representada como:

$y_{j d}=\varphi\left(x_{j}, y_{j d-1}\right)+v_{j}\left(\eta_{D}\right)$.

Com esse indicador-base de renda individual, a pobreza observada no tempo $d$ pode ser avaliada como uma função $P_{j d}$ de $y_{j d}$, tal que:
$P_{j d}=p\left(y_{j d}\right)=p\left(\varphi\left(x_{j}, y_{j d-1}\right)+v_{j}\left(\eta_{d}\right)\right)$,

onde $p($.) é a função de pobreza em uma data específica.

A medida de pobreza crônica é definida pelo componente $C_{j d}$ de $P_{j d}$, que é função apenas da renda permanente $\bar{y}_{j d}=\varphi\left(x_{j}, y_{j d-1}\right)$, de tal forma que: $C_{j d}=p\left(\bar{y}_{j d}\right)=p\left(\varphi\left(x_{j}, y_{j 0}, \eta_{1}, \ldots, \eta_{d-1}\right)\right)$, onde $y_{j 0}$ é a renda inicial de $j$ e $\left(\eta_{1}, \ldots, \eta_{d-1}\right)$ representa os estados da natureza realizados em períodos passados.

Não havendo choques na renda no tempo $d$, ou seja, $y_{j d}=\bar{y}_{j d}$ e $v_{j}\left(\eta_{d}\right)=0$, a pobreza observada neste período será igual à medida de pobreza crônica. Caso contrário, um componente residual na diferença entre $P_{j d}$ de $C_{j d}$ é identificado. Esse componente é definido como a medida de pobreza transitória:

$T_{j d}=P_{j d}-C_{j d}=p\left(\varphi\left(x_{j}, y_{j d-1}\right)+v_{j}\left(\eta_{d}\right)\right)_{-p}\left(\varphi\left(x_{j}, y_{j d-1}\right)\right)$. (4)

Para medidas intertemporais ou agregadas de pobreza, é feita uma suposição de aditividade sobre a função. Dessa forma, a pobreza de um indivíduo ao longo do tempo é dada pela média das medidas $P_{j d}$ observadas ao longo do tempo. O mesmo ocorre com as medidas intertemporais de pobrezas crônica e transitória.

Pelo modelo de Ribas e Machado (2007), como a renda permanente depende dos eventos ocorridos no passado, é atribuído à medida de pobreza crônica um componente de dependência de estado. ${ }^{2}$ Por outro lado, apesar de sua neutralidade sobre a pobreza crônica, a incerteza sobre os eventos no presente, ou simplesmente o risco incorrido sobre os indivíduos, se reflete nas medidas estática e intertemporal da pobreza transitória.

Dado $y_{j d-1}=p^{-1}\left(P_{j d-1}\right)$, a pobreza, assim como seus componentes, pode ser função da pobreza no período anterior. Logo,

\footnotetext{
${ }^{2}$ Essa dependência é evidenciada quando a probabilidade de ser pobre, em d, é consideravelmente maior entre aqueles que, em d-1, eram pobres do que entre os que eram não-pobres.
} 
no tempo d, a função de probabilidade de o indivíduo $j$ ser pobre pode ser representada como:

$$
P_{j d}=s_{j d} P_{j d-1}+e_{j d}\left(1-P_{j d-1}\right)
$$

onde $S_{j d}$ é a probabilidade de persistência na pobreza, dada a condição inicial no estado, e $e_{j d}$ é a probabilidade de transitar para a pobreza, dada a condição oposta no período anterior.

A partir dessa função, é possível calcular uma medida estacionária de pobreza, desde que $e_{j d}>0$ e $\left(s_{j d}-e_{j d}\right)<1$. Num ambiente estacionário, a propensão à pobreza, que representaria um status de pobreza crônica, é definida por:

$$
C_{j d} \equiv \lim _{d \rightarrow \infty} \frac{\sum_{d} P_{j d}}{d}=\frac{e_{j d}}{1-s_{j d}+e_{j d}} .
$$

Dado que $P_{j d}=C_{j d}+T_{j d}$, a medida de pobreza transitória no período $d$ é definida como:

$$
T_{j d} \equiv P_{j d}-C_{j d}=p\left(y_{j d}\right)-\frac{e_{j d}}{1-s_{j d}+e_{j d}}
$$

De acordo com as expressões (6) e (7), o fundamental, portanto, para estimar este modelo de decomposição é calcular as taxas $s_{j d}$ e $e_{j d}$.

\section{Modelo idade-período-coorte}

Normalmente, os efeitos de idade sobre avaliações individuais estão associados a processos biológicos, psicológicos, mudanças nos papéis sociais dos grupos etários e/ou implicações da teoria de capital humano. Os efeitos de período estão, por sua vez, relacionados a eventos específicos observados em cada ano, referentes a questões conjunturais. No entanto, essas não são as únicas dimensões básicas que definem a distribuição de um atributo em uma população. Existem ainda os chamados efeitos de coorte, geralmente associados a mudanças genéticas, na fecundidade e de comportamento entre gerações, além das interações históricas resultantes, em termos culturais, políticos e institucionais, entre ciclo de vida e período.

A classificação dos indivíduos em uma mesma coorte se dá para aqueles que nas- ceram em um mesmo intervalo de tempo e envelheceram juntos. Ou seja, o estudo de coorte se apóia na noção de que pessoas de idade $i$ no período $d$ são as mesmas que tinham a idade $i-1$ no período $d-1$. Porém, as diferenças entre as coortes não estão restritas somente às características do nascimento, tendendo também a serem localizadas por idade, seguindo possíveis eventos específicos do ciclo de vida (RYDER, 1965).

A inevitabilidade biológica do ciclo de vida individual, segundo Ryder (1965) não leva a necessárias implicações para a transformação da população. No entanto, o surgimento de novas coortes torna elegível o processo de mudança social, pois essas são menos restritas à história e mais capazes de adaptação ou de criação de novos modos de vida. De fato, as coortes apresentam heterogeneidade entre si, desenvolvendo padrões temporais distintos que respondem a estímulos específicos por período. Dessa forma, as variações temporais nas coortes não são as mesmas variações longitudinais período-por-período.

A análise específica de período implica o estudo de diferentes coortes no mesmo ponto no tempo, sendo que as mudanças em cada conjuntura dependem também da composição etária da população. Preston (1982) desenvolve um modelo de estática comparativa para mostrar que mudanças na vida de um indivíduo, ou de uma coorte, podem ser distintas daquelas ocorridas na população a que pertence. Segundo o autor, essa discrepância é gerada justamente pelas condições demográficas da população.

Portanto, para verificar as variações da pobreza e de sua composição empiricamente, a abordagem de análise deve conter as três dimensões críticas da análise longitudinal: idade do evento; período de sua ocorrência; e coorte dos indivíduos envolvidos. A análise idade-período-coorte subentende que todos os fatores, ao influenciarem a taxa de ocorrência de um evento, tal como a pobreza, podem ser agrupados significativamente nessas três categorias. A despeito das interações ou sobreposições existentes entre os três conjuntos de fatores, 
é assumido, implicitamente, que essas influências são menos importantes do que os efeitos principais associados a cada dimensão ${ }^{3}$ (WILMOTH, 1998).

Segundo Rios-Neto e Oliveira (1999), um modelo de "idade-período" (IP) permitiria apenas o cálculo de taxas por idade para cada período, enquanto um modelo "idadecoorte" (IC) possibilitaria o cálculo de taxas por idade para cada coorte. Um modelo IPC torna-se o ideal, pois, além de incorporar as três dimensões relevantes do processo demográfico, com seus efeitos puros sobre a variável de resposta, permite a replicação dos modelos IP e IC que o antecedem na árvore hierárquica de recursibilidade.

O período, assim como a idade e a coorte, não possui um efeito direto sobre a variável dependente, mas pode ser tratado meramente como um marco para outros fatores, nesse caso conjunturais, que afetariam um processo demográfico. Assim, o modelo IPC para pobreza possui o seguinte formato:

$$
f\left(P_{i d l}\right)=\mu+\theta_{i}+\theta_{d}+\theta_{l}+\xi_{i d l}
$$

onde $f($.) é uma função de transformação aplicada à taxa de pobreza $f($ ) observada na idade $i$, no período $d$, para a coorte $I$; o parâmetro $\mu$ estabelece um nível geral constante para $f\left(P_{i d l}\right)$; os parâmetros $\theta_{i}, \theta_{d}$ e $\theta$, descrevem padrões de mudança de $f\left(P_{i d l}\right)$ por idade, período e coorte, respectivamente; e o último termo, $\xi_{i d l}$, representa o erro aleatório da função.

No caso da estimação dos componentes crônico e transitório, o modelo está sujeito a restrição $P_{i d l}=C_{i d l}+T_{i d l}$, sendo $C_{i d l}$ e $T_{i d l}$ tratados como ortogonais entre si. A função de pobreza crônica é definida como:

$$
f\left(C_{i d l}\right)=\mu_{C}+\theta_{C, i}+\theta_{C, d}+\theta_{C, I}+\xi_{C, i d l}
$$

onde $\mu_{C}$ é a constante; $\theta_{C, i}, \theta_{C, d}$ e $\theta_{C, l}$ são os respectivos efeitos de idade, período e coorte sobre $f\left(C_{i d l}\right)$; e $\xi_{c, i d l}$ é o erro aleatório da função.
Dado que, para cada indivíduo, $P_{i d l}, C_{i d l} \in[0,1]$, a função $f($.$) possui um$ formato logístico, tal que:

$$
\begin{gathered}
E\left(P_{i d l} \mid i, d, l\right)=\frac{\exp \left(\mu+\theta_{i}+\theta_{d}+\theta_{l}\right)}{1+\exp \left(\mu+\theta_{i}+\theta_{d}+\theta_{l}\right)} \mathrm{e} \\
E\left(C_{i d l} \mid i, d, l\right)=\frac{\exp \left(\mu_{C}+\theta_{C, i}+\theta_{C, d}+\theta_{C, l}\right)}{1+\exp \left(\mu_{C}+\theta_{C, i}+\theta_{C, d}+\theta_{C, l}\right)} . \\
\text { Como } \quad T_{i d l}=P_{i d l}-C_{i d l}, \quad \text { então }
\end{gathered}
$$
$E\left(T_{i d l}\right)=E\left(P_{i d l}\right)-E\left(C_{i d l}\right)$. Logo, a função de pobreza transitória esperada pode ser representada como:

$$
\begin{aligned}
& E\left(T_{i d l} \mid i, d, l\right)= \frac{\exp \left(\mu+\theta_{i}+\theta_{d}+\theta_{l}\right)}{1+\exp \left(\mu+\theta_{i}+\theta_{d}+\theta_{l}\right)}- \\
& \frac{\exp \left(\mu_{C}+\theta_{C, i}+\theta_{C, d}+\theta_{C, l}\right)}{1+\exp \left(\mu_{C}+\theta_{C, i}+\theta_{C, d}+\theta_{C, l}\right)}
\end{aligned}
$$

Os efeitos marginais médios da idade, por exemplo, $E\left(P_{i d l} \mid i, d, l\right)$ sobre $E\left(C_{i d l} \mid i, d, l\right)$, e $E\left(T_{i d l} \mid i, d, l\right)$ são, respectivamente:

$$
\begin{aligned}
& \frac{\partial E\left(P_{i d l} \mid i, \bar{d}, \bar{l}\right)}{\partial i}=\frac{\exp \left(\mu+\theta_{i}+\theta_{d}+\theta_{l}\right)}{\left(1+\exp \left(\mu+\theta_{i}+\theta_{d}+\theta_{l}\right)\right)^{2}} \cdot \frac{\mathrm{d} \theta_{i}}{\mathrm{~d} i}, \\
& \frac{\partial E\left(C_{\text {ldl }} \mid i, \bar{d}, \bar{l}\right)}{\partial i}=\frac{\exp \left(\mu_{C}+\theta_{C, i}+\theta_{C, d}+\theta_{C, l}\right)}{\left(1+\exp \left(\mu_{C}+\theta_{C, i}+\theta_{C, d}+\theta_{C, l}\right)\right)^{2}} \cdot \frac{\mathrm{d} \theta_{C, i} \mathrm{e}}{\mathrm{d} i} \\
& \frac{\partial E\left(T_{i d l} \mid i, d, l\right)}{\partial i}=\frac{\partial E\left(P_{i d l} \mid i, \bar{d}, \bar{l}\right)}{\partial i}-\frac{\partial E\left(C_{\text {ldl }} \mid i, \bar{d}, \bar{l}\right)}{\partial i} .
\end{aligned}
$$

Os efeitos de mudança no período e na coorte $d=l+i$ são representados dessa mesma forma.

No modelo IPC, a exata conexão matemática entre idade, período e coorte tornao tautológico, no sentido de que toda vez que duas dimensões variarem, uma terceira será definida. Segundo Heckman e Robb (1985), qualquer esforço de identificação desses efeitos necessita de alguma hipótese adicional. Logo, essa identidade é uma dificuldade central na estimação dos parâmetros, sendo que a solução para o problema demanda uma escolha arbitrária, como

\footnotetext{
${ }^{3} \mathrm{~A}$ opção por se estimarem somente os efeitos principais de cada fator decorre, principalmente, do curto intervalo de tempo imposto pelos dados.
} 
a suposição de que parâmetros relativos a algum par de coortes, idades ou períodos sejam iguais (DEATON; PAXSON, 1993; RIOS-NETO; OLIVEIRA, 1999).

\section{Metodologia de estimação}

\section{Fonte dos dados e definição das medidas de pobreza}

Para as estimações das pobrezas crônica e transitória, no Brasil, ao longo do tempo, optou-se pelo uso dos microdados das PNADs de 1995, 1997, 1999, 2001 e 2003. A PNAD é um painel rotativo em que não se consegue acompanhar uma mesma pessoa ao longo do tempo, porém é possível acompanhar os dados de indivíduos em uma coorte. Segundo Firpo et al. (2003), há duas vantagens na utilização de dados de coorte em vez de dados em painel: ausência do problema de viés de sobrevivência da coorte na amostra, ou seja, sempre se consegue observar a mesma coorte em anos distintos; e minimização do erro de medida usualmente encontrado em dados em painel, uma vez que a informação da coorte é uma média. No entanto, os autores salientam que esses dados são um substituto imperfeito de dados longitudinais, pois pouco se pode dizer sobre a dinâmica interna às coortes das variáveis em observação, além de a validade de seus resultados depender da hipótese de que a população interna às coortes é constante.

Em cada ano, consideraram-se os indivíduos nascidos entre 1937 e 1968 (entre 27 e 58 anos em 1995), residentes em áreas urbanas $^{4}$ e com declaração de renda familiar não-negativa e de escolaridade (em anos de estudo). Deste universo, foram selecionados os chefes de família e seus filhos, cônjuges, outros parentes e agregados, excluindo os indivíduos que se declaram pensionistas, empregados ou parentes de empregado, segundo a classificação da PNAD.
$\mathrm{O}$ indicador base de bem-estar individual é a renda familiar bruta per capita. Para comparação entre indivíduos em diferentes regiões e períodos, esse indicador foi deflacionado espacialmente, de acordo com o índice proposto por Ferreira et al. (2000), e temporalmente, segundo o Índice Nacional de Preços ao Consumidor (INPC), como sugerido por Corseuil e Foguel (2002). A partir desse indicador, a pobreza é definida para aqueles indivíduos com renda familiar per capita abaixo de uma determinada linha de pobreza. Na definição dessa linha de referência, um dos aspectos a ser considerado é a relação entre pobreza e privações absoluta ou relativa (FOSTER, 1998). A linha de pobreza relativa é estabelecida como $60 \%$ da mediana, para cada ano, das rendas familiares per capita de todos os indivíduos (desde o zero ano de idade). A linha de pobreza absoluta é estabelecida nos $60 \%$ da medida do mesmo indicador, porém incluindo todos os períodos juntos.

Para obter o componente crônico para cada indivíduo, são calculadas a taxa de persistência na pobreza, $S_{j d}$, e a taxa de transição para a pobreza, $e_{j d}$. De acordo com Ribas e Machado (2007), primeiramente considera-se que, em $d$-1, a propensão à pobreza latente $P_{j d-1}^{*}$ do indivíduo $j$ é dada pela forma:

$$
P_{j d-1}^{*}=z_{j}^{\prime} \beta+v_{d-1}+u_{j d-1},
$$

em $d$, essa propensão é representada pela função:

$P_{j d}^{*}=\left\{\begin{array}{ccc}x_{j}^{\prime} \gamma_{1}+\vartheta_{1, d-1}+\varepsilon_{1 j d} & \text { se } & P_{j d-1}^{*}>0 \\ x_{j}^{\prime} \gamma_{2}+\vartheta_{2, d-1}+\varepsilon_{2 j d} & \text { se } & P_{j d-1}^{*} \leq 0\end{array}\right.$

e $\rho=\operatorname{corr}\left(u_{j d-1}, \varepsilon_{1 j d}+\varepsilon_{2 j d}\right)$ é a correlação entre os termos de erro das funções. O vetor $x_{j}$ descreve o indivíduo $j$ a partir de sua cor, sexo, escolaridade, região e período de nascimento; o vetor $z_{j}$ inclui as mesmas variáveis do vetor $x_{j}$, além das características de background familiar ${ }^{5}$ utilizadas como

\footnotetext{
${ }^{4}$ No trabalho, excluíram-se as famílias residentes em áreas rurais, optando-se por uma análise urbana, por três motivos: a existência de especificidades na pobreza rural em relação à análise de pobreza urbana; a pouca representatividade dos domicílios rurais na amostra da PNAD; e porque a pobreza no Brasil, segundo Silva e Tafner (2005), tornou-se, nos últimos anos, predominantemente urbana e metropolitana.

${ }_{5}^{5}$ Para as variáveis de background familiar, consideraram-se as informações referentes à escolaridade dos pais dos indivíduos, contidas na PNAD de 1996.
} 
instrumentos; $\beta, \gamma_{1}$ e $\gamma_{2}$ são vetores de parâmetros determinantes da condição inicial, da permanência e da transição, respectivamente, segundo características individuais, enquanto $v_{d-1}, \vartheta_{1, d-1}$ e $\vartheta_{2, d-1}$ são os vetores correspondentes aos efeitos conjunturais; $u_{j d-1}, \varepsilon_{1 j d}$ e $\varepsilon_{2 j d}$ são os termos de erro.

A estimação desse sistema de equações é realizada por meio da maximização da função de verossimilhança, especificada por Ribas e Machado (2007), utilizando dados em pseudopainel, agrupados de acordo com o vetor $x_{j}$. A diferença nas informações utilizadas pelos autores é que, neste trabalho, incluíram-se grupos de indivíduos nascidos entre 1937 e 1944, a fim de serem estimados, com maior extensão longitudinal, os efeitos de coorte e idade. Os resultados dos parâmetros estimados são apresentados na Tabela 5, constante no Anexo. A partir deles, é possível calcular as taxas $S_{j d}$ e $e_{j d}$, para cada indivíduo, da seguinte forma:

$$
s_{j d}=\frac{\Phi_{2}\left(z_{j}^{\prime} \beta+v_{d-1}, x_{j}^{\prime} \gamma_{1}+\vartheta_{1, d-1} ; \rho\right)}{\Phi\left(z_{j}^{\prime} \beta+v_{d-1}\right)}
$$

e

$$
e_{j d}=\frac{\Phi_{2}\left(-z_{j}^{\prime} \beta-v_{d-1}, x_{j}^{\prime} \gamma_{2}+\vartheta_{2, d-1} ;-\rho\right)}{\Phi\left(-z_{j}^{\prime} \beta-v_{d-1}\right)}
$$

onde $\varphi($.$) e \varphi_{2}($.$) são funções de proba-$ bilidade acumulada univariada e bivariada.

Cabe salientar que, a fim de realizar essa estimação para cada indivíduo dessa amostra, incluíram-se, ainda, as informações da PNAD de 1993. O acréscimo desse ano é necessário, pois o modelo de decomposição transitória-crônica prevê uma defasagem nos dados para captar a transição entre períodos.

\section{Formato do modelo IPC}

Para estimação do modelo IPC, as informações possuem um formato cross-section para indivíduos, empilhando os dados para os anos utilizados. Segundo Oliveira (2002), uma maneira de acompanhar cada coorte ao longo de repetidas pesquisas é observar os membros dessa coorte que foram selecionados aleatoriamente em cada ano.

Para cada indivíduo nesta cross-section, as variáveis explicativas das taxas de pobreza são a idade, o período e a coor-te, dispostas como no Quadro 1. Nesse qua-dro, as coortes de nascimento correspon-dem à diagonal da matriz $l=i-d+1$. As observações nos extremos do Quadro 1 não foram incluídas, pois não há estimativas de pobreza crônica para elas. Lembrando que o componente crônico da pobreza foi estimado por pseudopainel, em que o mesmo

QUADRO 1

\begin{tabular}{|c|c|c|c|c|c|}
\hline Idade & 1995 & 1997 & 1999 & 2001 & 2003 \\
\hline $27-28$ anos & 1 & & & & \\
\hline $29-30$ anos & 2 & 1 & & & \\
\hline 31-32 anos & 3 & 2 & 1 & & \\
\hline 33-34 anos & 4 & 3 & 2 & 1 & \\
\hline $35-36$ anos & 5 & 4 & 3 & 2 & 1 \\
\hline $37-38$ anos & 6 & 5 & 4 & 3 & 2 \\
\hline $39-40$ anos & 7 & 6 & 5 & 4 & 3 \\
\hline $41-42$ anos & 8 & 7 & 6 & 5 & 4 \\
\hline 43-44 anos & 9 & 8 & 7 & 6 & 5 \\
\hline $45-46$ anos & 10 & 9 & 8 & 7 & 6 \\
\hline $47-48$ anos & 11 & 10 & 9 & 8 & 7 \\
\hline $49-50$ anos & 12 & 11 & 10 & 9 & 8 \\
\hline $51-52$ anos & 13 & 12 & 11 & 10 & 9 \\
\hline 53-54 anos & 14 & 13 & 12 & 11 & 10 \\
\hline $55-56$ anos & 15 & 14 & 13 & 12 & 11 \\
\hline $57-58$ anos & 16 & 15 & 14 & 13 & 12 \\
\hline $59-60$ anos & & 16 & 15 & 14 & 13 \\
\hline $61-62$ anos & & & 16 & 15 & 14 \\
\hline $63-64$ anos & & & & 16 & 15 \\
\hline $65-66$ anos & & & & & 16 \\
\hline
\end{tabular}

Definição dos intervalos de idade, período e coorte

Fonte: Elaboração própria. 
grupo de indivíduos deve ser acompanhado do primeiro ao último período. Na Tabela 6, do Anexo, encontra-se a participação amostral de cada combinação IPC.

Com o problema de identificação no modelo, assumiu-se que as duas faixas de idade mais novas (27-28 e 29-30 anos) possuem os mesmos efeitos. Esta escolha, aparentemente arbitrária, é a mais plausível, dado o curto intervalo disponível para a análise. Contudo, um modelo com uma restrição alternativa sobre os efeitos de coorte também foi testado e não gerou resultados significativamente distintos. Este modelo alternativo não foi incluído neste artigo por uma questão de espaço.

Para estimação da função (8) de pobreza observada (absoluta e relativa), é utilizado um modelo logit e, para estimação dos efeitos sobre o componente crônico, da expressão (9), é utilizado um modelo linear, porém com uma transformação logística da variável explicada. Ambas funções são estimadas pelo método de máxima pseudoverossimilhança, devido ao desenho amostral das PNADs, como recomendado por Silva et al. (2002). Nesse método, as estimações requerem o uso, além do peso amostral, das variáveis de identificação do estrato geográfico e da unidade primária de amostragem para corrigir o erro amostral.
O conjunto de variáveis explicativas pode ser colocado de forma tanto contínua, caracterizando um modelo de funções polinomiais, quanto de dummies, definindo efeitos menos parametrizados na combinação IPC. Attanasio e Jappelli (1998), por exemplo, empregam polinômios na estimação dos efeitos idade, período e coorte sobre a variância da utilidade marginal do consumo. Esse tipo de especificação é vantajoso porque a pobreza pode variar entre coortes, períodos e idades de forma não constante. Assim, o polinômio até terceira ordem daria conta dos efeitos nãolineares. Segundo Firpo et al. (2003), a escolha da melhor especificação a ser estimada consiste em um trade-off entre mais graus de liberdade, no modelo com polinômios, e mais flexível, no modelo com as variáveis binárias, uma vez que não se impõe uma estrutura ad hoc para o comportamento desse efeito.

Os Gráficos 1 e 2 e a Tabela 1 descrevem as medidas agregadas de pobreza absoluta e relativa, juntamente com seus componentes, por faixa de idade, coorte de nascimento e período, não interagindo essas dimensões. Ao se considerar somente a idade do indivíduo, no Gráfico 1, verificase que a pobreza, tanto absoluta quanto relativa, possui uma trajetória média decres-

GRÁFICO 1

Medidas de pobreza absoluta e relativa observadas e seus componentes, por idade Brasil-1995-2003

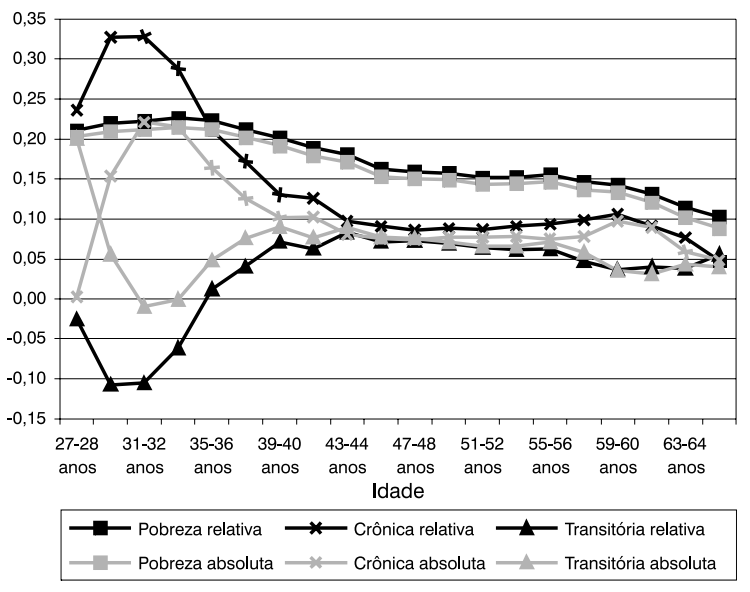

Fonte: IBGE. Pesquisa Nacional por Amostra de Domicílios - PNAD 1995 a 2003. Elaboração própria. 
TABELA 1

Pobrezas absoluta e relativa observadas, seus componentes e idade média de incidência por período Brasil-1996-2003

\begin{tabular}{|c|c|c|c|c|c|c|c|}
\hline \multirow[b]{2}{*}{ Anos } & & \multicolumn{3}{|c|}{ Pobreza relativa } & \multicolumn{3}{|c|}{ Pobreza absoluta } \\
\hline & & Observada & Crônica & Transitória & Observada & Crônica & Transitória \\
\hline 1995 & & 0,1886 & 0,1159 & 0,0727 & 0,1803 & 0,0012 & 0,1790 \\
\hline 1997 & & 0,1882 & 0,2337 & $-0,0455$ & 0,1764 & 0,1762 & 0,0002 \\
\hline 1999 & & 0,1847 & 0,1719 & 0,0128 & 0,1777 & 0,2114 & $-0,0337$ \\
\hline 2001 & & 0,1854 & 0,1590 & 0,0264 & 0,1733 & 0,1007 & 0,0726 \\
\hline 2003 & & 0,1745 & 0,0775 & 0,0970 & 0,1644 & 0,0724 & 0,0919 \\
\hline Total & & 0,1842 & 0,1507 & 0,0334 & 0,1743 & 0,1115 & 0,0628 \\
\hline $\begin{array}{l}\text { Idade } \\
\text { média/ano }\end{array}$ & Amostra & & & Ponderad & por medida & & \\
\hline 1995 & 39,2 & 38,1 & 35,4 & 40,5 & 38,1 & 35,3 & 39,5 \\
\hline 1997 & 41,1 & 40,2 & 38,0 & 42,6 & 40,2 & 38,3 & 42,4 \\
\hline 1999 & 43,1 & 41,8 & 39,7 & 44,2 & 41,8 & 40,5 & 43,7 \\
\hline 2001 & 44,9 & 43,2 & 41,3 & 45,8 & 43,1 & 41,7 & 45,3 \\
\hline 2003 & 46,9 & 44,9 & 42,8 & 48,3 & 44,7 & 43,4 & 47,8 \\
\hline Total & 43,1 & 41,7 & 39,5 & 44,3 & 41,6 & 39,9 & 43,8 \\
\hline
\end{tabular}

Fonte: IBGE. Pesquisa Nacional por Amostra de Domicílios - PNAD 1995 a 2003. Elaboração própria.

GRÁFICO 2

Medidas de pobreza absoluta e relativa observadas e seus componentes, por coorte Brasil-1995-2003

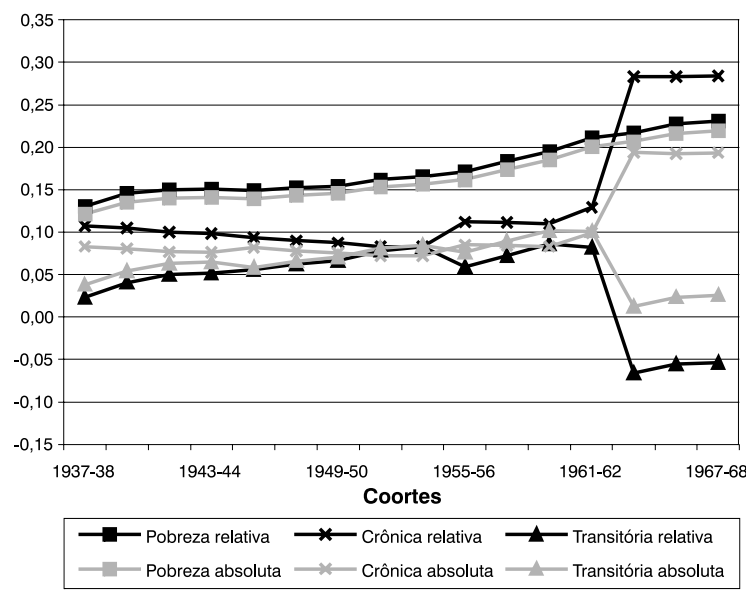

Fonte: IBGE. Pesquisa Nacional por Amostra de Domicílios - PNAD 1995 a 2003. Elaboração própria.

cente ao longo do ciclo de vida, em decorrência da distribuição do componente crônico. Já o componente transitório parece possuir uma trajetória inversa, particularmente a partir dos 31 anos de idade. De fato, em todos os períodos estudados, a idade média de pobreza crônica está abaixo da idade média da amostra, enquanto a média de idade ponderada pelo componente transitório está acima dessa marca (Tabela 1). Verifica-se uma redução da pobreza crônica ao longo do tempo, em contrapartida a um aumento na transitória, excluindo-se o ano de $1995 .{ }^{6}$

${ }^{6} \mathrm{O}$ ano de 1995 pode ser tratado como um período atípico, devido à implantação do Plano Real, em 1994, e suas conseqüências conjunturais. 
No agregado das coortes de nascimento, a pobreza observada apresenta tendência ascendente, no sentido dos grupos mais jovens, assim como no ciclo de vida (Gráfico 2). Ambos efeitos, porém, se confundem, não sendo possível definir o que é trajetória no ciclo de vida e o que é tendência entre as gerações. Em termos de composição, iden-tifica-se uma mudança significativa entre o grupo de indivíduos nascidos antes e de-pois de 1963, na qual a pobreza passou a ser essencialmente crônica para as gerações mais novas.

\section{Resultados do modelo IPC}

As estimações do modelo IPC aplicado à pobreza observada e ao seu componente crônico foram realizadas de duas maneiras: tratando as variáveis explicativas como um conjunto de dummies ou de forma contínua. Assim, busca-se garantir alguma robustez às tendências estimadas de ciclo de vida, período e coorte. Pela maior clareza nos resultados e, portanto, maior facilidade de interpretação, são apresentados nessa seção somente os resultados do modelo de polinômios, nas Tabelas 2 e 3 . As estimações por dummies encontram-se nas Tabelas 7 e 8 do Anexo.

Pelas regressões estimadas segundo as definições de privações absoluta (Tabela 2) e relativa (Tabela 3 ), identifica-se que as medidas de pobreza total não respondem significativamente às variações conjunturais. Esse resultado é condizente também com as regressões utilizando dummies para os períodos. Ou seja, ao longo do tempo, a pobreza é somente determinada pela combinação das características de idade e coorte de nascimento. De fato, no Brasil, desde 1994, não é constatado nenhum choque conjuntural expressivo (positivo ou negativo) que cause uma mudança brusca

TABELA2

Resultados das regressões do modelo IPC de pobreza absoluta, efeitos polinomiais Brasil - 1995-2003

\begin{tabular}{|c|c|c|c|c|c|c|c|}
\hline \multirow{3}{*}{ Variáveis } & \multicolumn{7}{|c|}{ Pobreza absoluta } \\
\hline & \multicolumn{3}{|c|}{ Total } & \multicolumn{3}{|c|}{ Crônica } & \multirow{2}{*}{$\begin{array}{r}\text { Transitória } \\
\text { ef. marg }\end{array}$} \\
\hline & ef. marg. & coef. & $P>|t|$ & ef. marg. & coef. & $P>|t|$ & \\
\hline Idade & $-0,00301$ & $-0,02117$ & 0,267 & $-0,01320$ & $-0,13328$ & 0,000 & 0,01019 \\
\hline Idade ao quadrado & $-0,00019$ & $-0,00133$ & 0,001 & 0,00026 & 0,00267 & 0,000 & $-0,00045$ \\
\hline Idade ao cubo & 0,00000 & 0,00000 & 0,653 & $-0,00001$ & $-0,00006$ & 0,000 & 0,00001 \\
\hline Período & 0,00098 & 0,00692 & 0,881 & 0,66632 & 6,72676 & 0,000 & $-0,66534$ \\
\hline Período ao quadrado & 0,00138 & 0,00972 & 0,338 & $-0,11655$ & $-1,17658$ & 0,000 & 0,11793 \\
\hline Período ao cubo & $-0,00010$ & $-0,00071$ & 0,277 & 0,00619 & 0,06253 & 0,000 & $-0,00629$ \\
\hline Coorte & 0,00318 & 0,02238 & 0,570 & $-0,01960$ & $-0,19787$ & 0,000 & 0,02278 \\
\hline Coorte ao quadrado & $-0,00231$ & $-0,01624$ & 0,012 & 0,00049 & 0,00495 & 0,082 & $-0,00280$ \\
\hline Coorte ao cubo & 0,00011 & 0,00080 & 0,020 & $-0,00001$ & $-0,00009$ & 0,567 & 0,00012 \\
\hline Dummy coortes 196368 & 0,14836 & 1,29316 & 0,000 & 0,60909 & 6,14900 & 0,000 & $-0,46074$ \\
\hline Interação dummy coorte & $-0,04201$ & $-0,29522$ & 0,000 & $-0,08953$ & $-0,90387$ & 0,000 & 0,04752 \\
\hline Inter. dummy coorte quadr. & 0,00381 & 002680 & 0000 & 0,00395 & 003990 & 0000 & $-0,00014$ \\
\hline Inter. dummy coorte cubo & $-0,00013$ & $-0,00094$ & 0,007 & $-0,00005$ & $-0,00049$ & 0,002 & $-0,00008$ \\
\hline Constante & & $-0,15125$ & 0,766 & & $-9,99174$ & 0,000 & \\
\hline Número de observações & 512.690 & & & 512.690 & & & \\
\hline Número de estratos & 2.219 & & & 2.219 & & & \\
\hline Número de PSUs & 25.528 & & & 25.528 & & & \\
\hline Tamanho da população & $2.31 E+08$ & & & $2.31 E+08$ & & & \\
\hline Graus de liberdade & 23309 & & & 23309 & & & \\
\hline$F(13,23297)$ & 168,62 & & & 13264,45 & & & \\
\hline Prob $>F$ & 0,0000 & & & 0,0000 & & & \\
\hline
\end{tabular}


no patamar de pobreza. Dessa forma, a diminuição na incidência do problema, em anos recentes (IBRE/FGV, 2005), pode estar mais ligada a uma tendência de mudança nas coortes do que de mudança no ambiente político-econômico. Ou ainda, pode-se pensar que os choques conjunturais, ao longo do tempo, estão se refletindo sobre os indivíduos de forma mais persistente, por meio de alterações nas coortes.

Apesar de não ser constatado um efeito puro de período sobre as pobrezas absoluta e relativa, em termos de composição transitória-crônica, identifica-se uma tendência, independente da idade e da coorte, significativa ao longo do tempo. Essa tendência é de aumento do componente crônico, em contraponto a uma redução semelhante na parte transitória. No entanto, esse processo não segue uma trajetória crescente, pois os efeitos de períodos são significativa- mente côncavos. O formato da função de período estimada aponta, na realidade, para uma estacionariedade na diferença entre componentes, dando a entender que a tendência identificada foi causada pela mudança brusca de composição ocorrida entre 1995 e 1997.

Em relação ao efeito puro das coortes, em que, a princípio, o efeito conjuntural está estigmatizado, verifica-se uma tendência decrescente das pobrezas total, absoluta e relativa. Quanto aos componentes, um processo de redução mais acelerado é identificado em termos crônicos. As medidas de pobreza transitória, pelo contrário, tendem a aumentar com o passar das gerações. Cabe salientar que todas essas tendências não apresentam monotonicidade. A partir das estimações dos efeitos por variáveis binárias, foi possível constatar uma quebra estrutural de composição entre as coortes

TABELA 3

Resultados das regressões do modelo IPC de pobreza relativa, efeitos polinomiais Brasil-1995-2003

\begin{tabular}{|c|c|c|c|c|c|c|c|}
\hline \multirow{3}{*}{ Variáveis } & \multicolumn{7}{|c|}{ Pobreza relativa } \\
\hline & \multicolumn{3}{|c|}{ Total } & \multicolumn{3}{|c|}{ Crônica } & \multirow{2}{*}{$\begin{array}{r}\text { Transitória } \\
\text { ef. marg. }\end{array}$} \\
\hline & ef. marg. & coef. & $P>|t|$ & ef. marg. & coef. & $P>|t|$ & \\
\hline Idade & $-0,00399$ & $-0,02681$ & 0,155 & $-0,02283$ & $-0,17835$ & 0,000 & 0,01884 \\
\hline Idade ao quadrado & $-0,00024$ & $-0,00159$ & 0,000 & 0,00035 & 0,00270 & 0,000 & $-0,00058$ \\
\hline Idade ao cubo & 0,00000 & 0,00001 & 0,133 & $-0,00001$ & $-0,00005$ & 0,000 & 0,00001 \\
\hline Período & 0,00305 & 0,02048 & 0,655 & 0,15277 & 1,19333 & 0,000 & $-0,14972$ \\
\hline Período ao quadrado & 0,00126 & 0,00850 & 0,397 & $-0,02324$ & $-0,18151$ & 0,000 & 0,02450 \\
\hline Período ao cubo & $-0,00009$ & $-0,00063$ & 0,329 & 0,00097 & 0,00757 & 0,000 & $-0,00106$ \\
\hline Coorte & 0,00447 & 0,03004 & 0,431 & $-0,01872$ & $-0,14621$ & 0,000 & 0,02319 \\
\hline Coorte ao quadrado & $-0,00262$ & $-0,01760$ & 0,005 & $-0,00088$ & $-0,00689$ & 0,011 & $-0,00174$ \\
\hline Coorte ao cubo & 0,00013 & 0,00084 & 0,011 & 0,00005 & 0,00035 & 0,017 & 0,00008 \\
\hline Dummy coortes 196368 & 0,14500 & 1,18407 & 0,000 & 0,77457 & 6,05044 & 0,000 & $-0,62957$ \\
\hline Interação dummy coorte & $-0,04234$ & $-0,28452$ & 0,000 & $-0,12575$ & $-0,98226$ & 0,000 & 0,08341 \\
\hline Inter. dummy coorte quadr. & 0,00401 & 0,02695 & 0,000 & 0,00674 & 0,05267 & 0,000 & $-0,00273$ \\
\hline Inter. dummy coorte cubo & $-0,00014$ & $-0,00097$ & 0,004 & $-0,00012$ & $-0,00095$ & 0,000 & $-0,00002$ \\
\hline Constante & & 0,05665 & 0,910 & & 0,38416 & 0,144 & \\
\hline Número de observações & 512.690 & & & 512.690 & & & \\
\hline Número de estratos & 2.219 & & & 2.219 & & & \\
\hline Número de PSUs & 25.528 & & & 25.528 & & & \\
\hline Tamanho da população & $2,31 E+08$ & & & $2,31 E+08$ & & & \\
\hline Graus de liberdade & 23.309 & & & 23.309 & & & \\
\hline$F(13,23297)$ & 168,05 & & & 7355,55 & & & \\
\hline Prob $>F$ & 0,0000 & & & 0,0000 & & & \\
\hline
\end{tabular}

Fonte: IBGE. Pesquisa Nacional por Amostra de Domicílios - PNAD 1995 a 2003. Elaboração própria. 
nascidas antes e depois de 1963. A despeito da mudança de patamar ocorrida entre esses dois grupos de indivíduos, de uma maneira geral, as coortes mais novas tendem a ter um componente transitório maior. Ou seja, se, no que se refere a período, a pobreza crônica aumentou recentemente, em termos de coorte a pobreza transitória é a que vem crescendo.

No que diz respeito a ciclo de vida, as funções de pobreza total e de seu componente crônico apresentam formato negativamente inclinado, de efeito mais acentuado para a segunda medida. Esse resultado leva à intuição de que a idade média de privação crônica, ao longo do ciclo de vida, é menor do que a idade média do total da pobreza, que, por sua vez, é inferior à idade média da população. Uma das causas para esse resultado está no fato de a taxa de mortalidade ser, provavelmente, maior onde a pobreza crônica é mais concentrada, fazendo com que as coortes percam, ao longo do tempo, grande parte dos indivíduos nessa situação. Ao contrário do componente crônico, a pobreza transitória, com função ascendente no ciclo de vida, possui uma idade média mais elevada.

\section{Projeções}

Por meio do modelo IPC, é possível projetar a distribuição de qualquer atributo de caráter demográfico em uma população, com detalhamento no desenho dos cenários simulados. Para extrapolar previsões futuras das medidas de pobreza, algumas suposições são consideradas. Primeiramente, assume-se que o perfil etário longitudinal da pobreza é constante e igual aos respectivos coeficientes estimados nas regressões (Tabelas 2 e 3), ou seja, os efeitos de idade não se alteram no futuro. Logo, as projeções são realizadas considerando mudanças apenas nas dimensões de período e coorte, seguindo as tendências observadas nos efeitos puros por meio de seus coeficientes estimados.

Com a identificação dessas tendências, os efeitos de seis novas coortes e de três novos períodos são calculados, como ilustrado nos Gráficos 3 e 4. A partir disso, projetam-se medidas de pobreza agregada e de seus componentes para a população entre 29 e 66 anos de idade, para 2005, 2007 e 2009. A extrapolação de previsões da pobreza segue a mesma lógica da estimação do modelo IPC. Ou seja,

GRÁFICO 3

Efeitos projetados de coorte sobre a função logística das medidas Brasil - 1995-2003

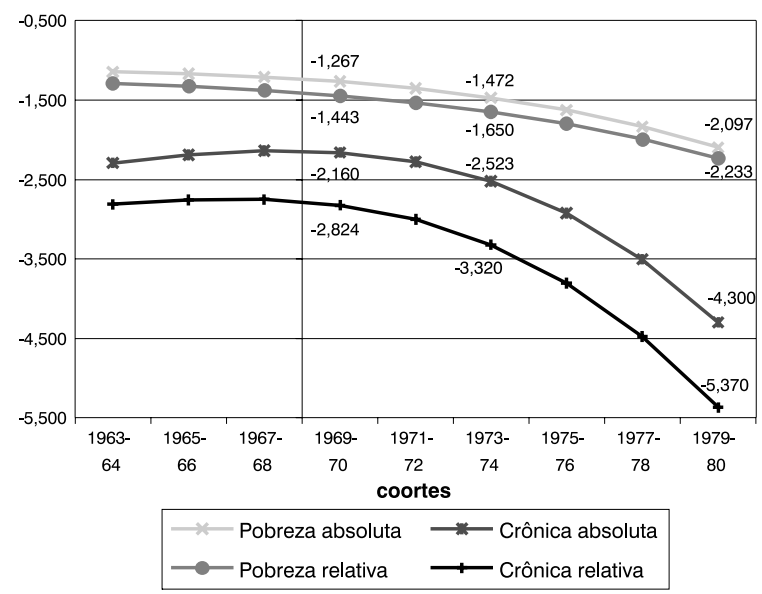

Fonte: IBGE. Pesquisa Nacional por Amostra de Domicílios - PNAD 1995 a 2003. Elaboração própria. 
GRÁFICO 4

Efeitos projetados de período sobre a função logística das medidas

Brasil - 1995-2003

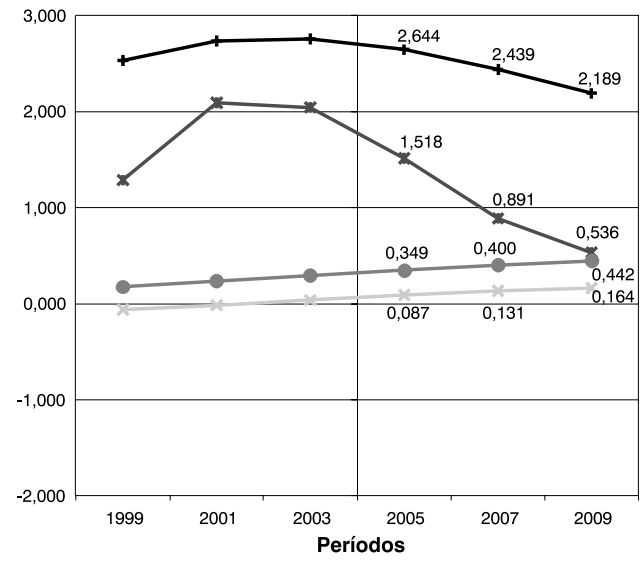

- Pobreza absoluta $\longrightarrow$ Crônica absoluta
- Pobreza relativa $\longrightarrow$ Crônica relativa

Fonte: IBGE. Pesquisa Nacional por Amostra de Domicílios - PNAD 1995 a 2003. Elaboração própria.

TABELA 4

Medidas de pobreza absoluta e relativa projetadas para população entre 29 e 66 anos Brasil-2005-2009

\begin{tabular}{lccc}
\hline Pobrezas & $\mathbf{2 0 0 5}$ & $\mathbf{2 0 0 7}$ & $\mathbf{2 0 0 9}$ \\
\hline Absoluta & & & \\
Total & 0,2198 & 0,2081 & 0,1935 \\
Crônica & 0,1056 & 0,0515 & 0,0300 \\
Transitória & 0,1142 & 0,1565 & 0,1635 \\
Relativa & & & \\
Total & 0,2300 & 0,2177 & 0,2028 \\
Crônica & 0,1188 & 0,0806 & 0,0490 \\
Transitória & 0,1112 & 0,1371 & 0,1538 \\
\hline
\end{tabular}

Fonte: IBGE. Pesquisa Nacional por Amostra de Domicílios - PNAD 1995 a 2003. IBGE (2004). Elaboração própria.

primeiramente, é projetada a pobreza total e, em seguida, a crônica. A medida do componente transitório é dada pela diferença entre as duas medidas anteriores.

A partir dos Gráficos 3 e 4, o cenário formulado para projeção é aquele em que a pobreza diminui quase que linearmente entre as gerações, porém de forma relativamente lenta. Para os efeitos de coorte sobre os componentes crônicos, uma tendência de redução maior é esperada, principalmente em termos relativos. Quanto à tendência da pobreza entre os períodos, as variações das medidas totais são seme-
Ihantes entre as definições relativa e absoluta, sendo linearmente crescente. No entanto, no que se refere à composição, verifica-se uma redução mais acelerada do componente crônico em termos absolutos do que relativos. Esse cenário, na prática, supõe que mudanças na condição crônica relativa ocorrem de forma mais lenta, em termos conjunturais, do que na condição absoluta.

Nos cálculos das previsões de medidas agregadas para 2005, 2007 e 2009 (Tabela 4), são utilizadas as projeções da população brasileira realizadas pelo IBGE (2004). 
De acordo com o cenário descrito, a previsão de redução na pobreza é em torno de 2,7 pontos percentuais em quatro anos, em termos tanto absolutos quanto relativos. Apesar dessa pequena mudança nas medidas totais de privação, projeta-se para os componentes crônicos agregados uma considerável redução, aumentando, por outro lado, a transitoriedade dos indivíduos às pobrezas absoluta e relativa. Ou seja, espera-se que, cada vez mais, a incidência de pobreza provenha do risco de transição das pessoas entre estados e não tanto de sua condição permanente.

Para ilustrar a distribuição etária da pobreza nos períodos projetados, os Gráficos 5 e 6 apresentam as medidas esperadas por idade e ano. Independente da definição de privação, a tendência esperada da distribuição da pobreza é de redução, entre as pessoas com mais de 46 anos e, principalmente, menos de 39 anos. Logo, a

GRÁFICO 5

Perfil etário da pobreza absoluta por período projetado Brasil-1995-2003

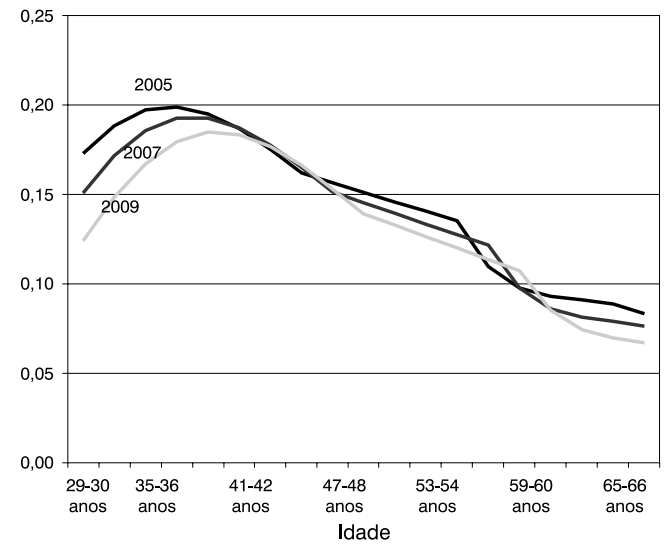

Fonte: IBGE. Pesquisa Nacional por Amostra de Domicílios - PNAD 1995 a 2003. Elaboração própria.

GRÁFICO 6

Perfil etário da pobreza relativa por período projetado Brasil-1995-2003

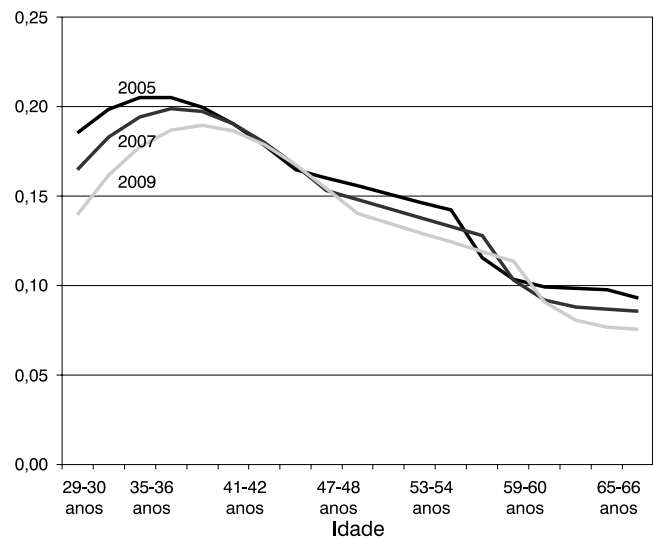

Fonte: IBGE. Pesquisa Nacional por Amostra de Domicílios - PNAD 1995 a 2003. Elaboração própria. 
GRÁFICO 7

Perfis etários das pobrezas absolutas crônica e transitória, por período projetado Brasil - 1995-2003

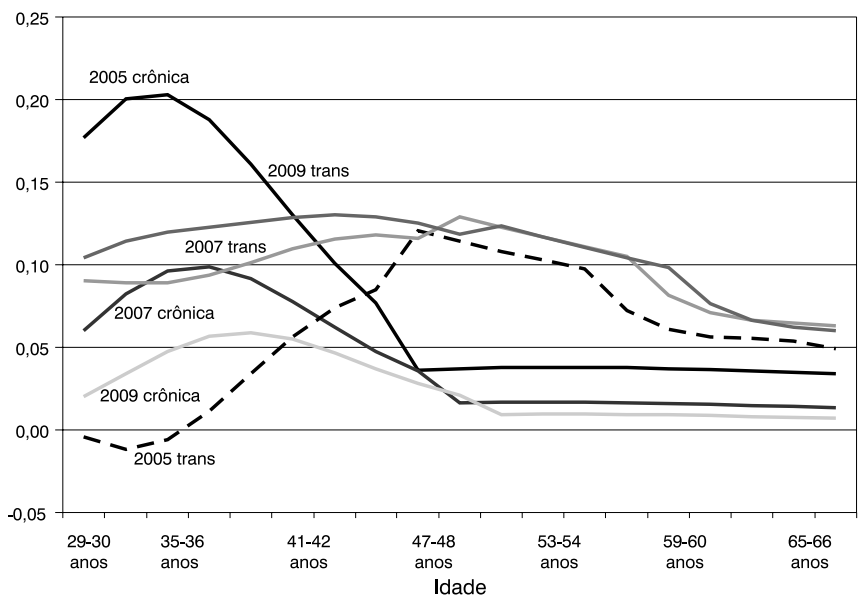

Fonte: IBGE. Pesquisa Nacional por Amostra de Domicílios - PNAD 1995 a 2003. Elaboração própria.

GRÁFICO 8

Perfis etários das pobrezas relativas crônica e transitória, por período projetado Brasil - 1995-2003

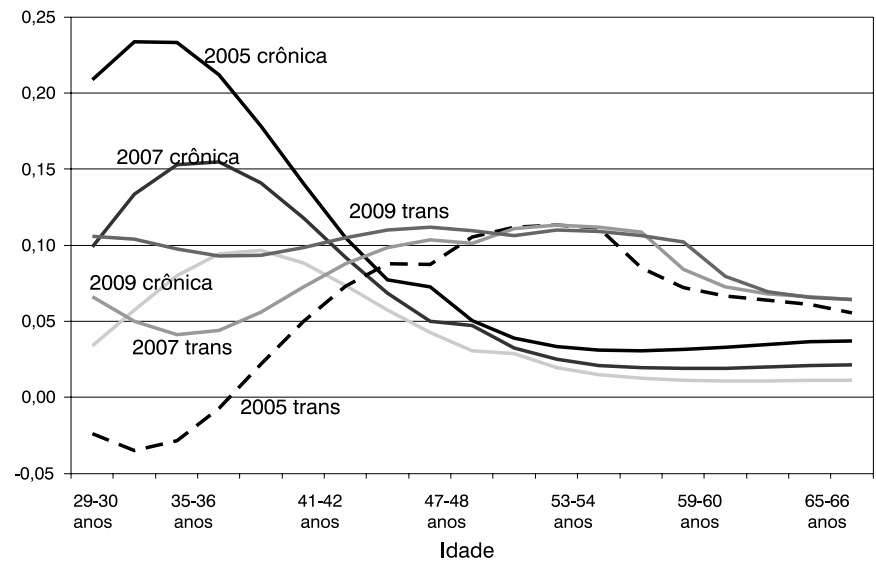

Fonte: IBGE. Pesquisa Nacional por Amostra de Domicílios - PNAD 1995 a 2003. Elaboração própria.

tendência projetada aponta para um possível aumento na idade média da pobreza.

Os Gráficos 7 e 8 mostram a distribuição etária da composição esperada da pobreza. A constatação sobre esses gráficos é que a tendência das medidas absolutas e relativas é de redução da privação crônica para todas as idades, principalmente nas mais jovens. Esse processo poderia levar a uma distribuição mais uniforme da pobreza crônica entre as faixas etárias, aumentando a idade média de incidência desse com- ponente. Já a pobreza transitória, que, inicialmente, apresenta uma distribuição côncava, tende a um formato negativamente inclinado, elevando significativamente sua incidência entre as faixas de idade mais jovens.

\section{Conclusão}

No início deste trabalho, demonstra-se que, além da possibilidade de decomposição do indicador de pobreza em duas 
partes distintas, pode-se identificar uma diferenciação entre tendências observadas ao longo dos períodos, para toda uma população, e ao longo do ciclo de vida, para pessoas em uma coorte específica. Portanto, recorre-se a um modelo de estimação idade-período-coorte (IPC) para captar esses processos possivelmente diferenciados.

Retomando os resultados do modelo de IPC estimado, conclui-se que, em anos mais recentes, a redução da incidência da pobreza deve-se mais a um efeito de mudanças entre gerações do que de alterações específicas nos períodos. Em relação à composição da pobreza, o processo mais acelerado de redução é do componente crônico. Em contrapartida, o componente transitório apresenta uma tendência significativa de aumento ao longo do tempo.

Nas projeções simuladas, tornam-se claras as tendências de aumento do componente transitório, principalmente entre a população mais jovem, em aspecto de privação tanto absoluta quanto relativa, mesmo com a redução na incidência total de pobreza. Logo, outra conclusão deste trabaIho é que, ao longo do tempo, a incidência de pobreza na população brasileira se dará cada vez menos pela condicionalidade média à baixa renda e cada vez mais pela vulnerabilidade à transição de estados. Persistindo essa tendência, espera-se uma inversão no cenário apontado por Ribas e Machado (2007), em que a situação crônica era o principal responsável pela condição de pobreza da maioria da população de baixa renda.

Uma explicação para a mudança de composição da pobreza pode ser a maior escolaridade das coortes mais novas (MARTELETO, 2005; VELEZ et al., 2001), que reduzem seu componente crônico por meio da maior acumulação de capital humano, ligada às recentes mudanças no mercado de trabalho, gerando maior mobilidade e risco de desemprego. Segundo Marió (2005), os jovens alcançaram níveis educacionais mais altos, mas isso não se traduziu em melhorias no emprego, principalmente entre aqueles sem formação superior. De acordo com Chahad e Macedo (2003), a partir da década de 90 , o mercado de trabalho brasileiro caracterizou-se por uma ampliação nas taxas de desemprego e rotatividade e das relações informais de trabalho. Para Marió (2005), a população de baixa renda percebe essas mudanças com uma expansão no grau de vulnerabilidade e incerteza.

Outra explicação para o aumento da pobreza transitória pode ser a crescente participação feminina no mercado de trabalho (RIOS-NETO; OLIVEIRA, 1999; LEME; WAJNMAN, 2003) e como chefes de família (MEDEIROS; OSÓRIO, 2002). Como apontado por Ribas e Machado (2007), pessoas em famílias chefiadas por mulheres estão mais sujeitas à pobreza transitória.

Em todo caso, o processo identificado de aumento da pobreza transitória e, conseqüentemente, da percepção dos riscos incorridos por famílias e indivíduos possui uma implicação de política clara. De acordo com Wood (2003), autoridades corretamente direcionadas para o combate à pobreza são aquelas que buscam criar as condições necessárias para pessoas saírem da sua condição de privação para um estado mais seguro, sustentado e não-vulnerável de bem-estar. No entanto, muitos governos fracassam nessa busca, pois acabam envolvidos na reprodução das condições sociais, econômicas e políticas que criam barreiras de incerteza e insegurança ao movimento de redução da pobreza.

Portanto, programas sociais que visem redução da desigualdade e acumulação de capital humano por via de transferência de renda devem ser acompanhados de medidas que garantam maior segurança a famílias e seus indivíduos. Nesse aspecto, a aquisição e a legalização de posse de ativos têm papel fundamental na redução dos riscos provocados pelas intempéries econômicas sobre a volatilidade da renda, facilitando o acesso ao crédito e aumentando a capacidade de respostas a choques, de maneira geral.

Além da questão da proteção social via mercado de crédito, o sistema de seguridade social no Brasil, que envolve os benefícios de seguro-desemprego e o Fundo de Garantia por Tempo de Serviço (FGTS), pode ser repensado de modo a incluir os 
trabalhadores do setor informal, que representam mais da metade da força de trabalho. No Brasil, segundo Cardoso e Jaccoud (2005), a ausência de ações mais amplas no campo das políticas de proteção ao trabaIhador e às suas famílias tem minimizado os

\section{Referências bibliográficas}

ARBACHE, J. S. Pobreza e mercados no Brasil. Pobreza e mercados no Brasil: uma análise de iniciativas de políticas públicas. Brasília: Cepal, DFID, 2003, p.9-115.

ATTANASIO, O. P.; JAPPELLI, T. International choice and the cross-sectional variance of marginal utility. Cambridge, Mass.: NBER, 1998 (Working paper, 6560).

CARDOSO Jr., J. C.; JACCOUD, L. Políticas sociais no Brasil: organização, abrangência e tensões da ação estatal. In: JACCOUD, L. (Org.). Questão social e políticas sociais no Brasil contemporâneo. Brasília: Ipea, 2005, p.181-260.

CHAHAD, J. P. Z.; MACEDO, R. A evolução do emprego no período 1992-2001 e a ampliação do mercado formal brasileiro desde 1999. In: CHAHAD, J. P. Z.; PICCHETTI, P. (Orgs.). Mercado de trabalho no Brasil. São Paulo: LTr, 2003, p.213-245.

CORSEUIL, C. H.; FOGUEL, M. N. Uma sugestão de deflatores para rendas obtidas a partir de algumas pesquisas domiciliares do IBGE. Rio de Janeiro: Ipea, 2002 (Texto para discussão, 897).

DEATON, A.; PAXSON, C. Saving, growth and aging in Taiwan. Cambridge, Mass: NBER, 1993 (Working paper, 4330).

FERREIRA, F. H. G.; LANJOUW, P.; NERI, M. A new poverty profile for Brazil using PPV, PNAD and census data. Rio de Janeiro: PUC, Departamento de Economia, 2000 (Texto para discussão, 418).

FIRPO, S. P.; GONZAGA, G.; NARITA, R. Decomposição da evolução da desigualdade de renda no Brasil em efeitos idade, período e coorte. Pesquisa e Planejamento Econômico, v.33, n.2, p.211252, 2003. efeitos agregados dos programas públi-cos de seguro-desemprego, intermediação da mão-de-obra, formação profissional e geração de emprego e renda a partir do microcrédito e do desenvolvimento de experiências locais.

FOSTER, J. E. What is poverty and who are the poor? Redefinition for the United States in the 1990's: absolute versus relative poverty. The American Economic Review, v.88, n.2, p.335-341, May 1998.

GAIHA, R.; DEOLALIKAR, A. B. Persistent, expected and innate poverty: estimates for semi arid rural South India. Cambridge Journal of Economics, v.17, n.4, p.409-421, 1993.

GLENN, N. D. Cohort analysts' futile quest: statistical attempts to separate age, period, and cohort effects. American Sociological Review, v.41, n.5, p.900-904, 1976.

GOLDSTEIN, H. Age, period and cohort effects: a confounded confusion. Bulletin in Applied Statistics, v.6, n.1, p.19-24, 1979.

HECKMAN, J.; ROBB, R. Using longitudinal data to estimate age, period and cohort effects in earnings equations. In: MASON, W. M.; FIENBERG, S. E. (Eds.). Cohort analysis in social research beyond the identification problem. New York: Academic Press, 1985, p.137-150.

IBGE. Pesquisa Nacional por Amostras de Domicílios - PNAD. Rio de Janeiro: IBGE, 1993-2003.

. Projeção da população do Brasil por sexo e idade para o período 19802050: revisão 2004. Rio de Janeiro: IBGE, 2004.

IBRE/FGV. Miséria em queda: mensuração, monitoramento e metas. Rio de Janeiro: Centro de Políticas Sociais do IBRE/FGV, 2005.

JALAN, J.; RAVALLION, M. Is transient poverty different? Evidence for rural China. Journal of Development Studies, v.36, n.6, p.82-98, 2000. 
JALAN, J.; RAVALLION, M. Transient poverty in postreform rural China. Journal of Comparative Economics, v.26, n.2, p.338357, 1998.

LEME, M. C. S.; WAJNMAN, S. Efeitos de período, coorte e ciclo de vida na participação feminina no mercado de trabalho brasileiro. In: WAJNMAN, S.; MACHADO, A. F. (Orgs.). Mercado de trabalho: uma análise a partir das pesquisas domiciliares no Brasil. Belo Horizonte: UFMG, 2003, p.49-65 (Coleção população e economia).

MARIÓ, E. G. Conclusões e recomendações. In: MARIÓ, E. G.; WOOLCOCK, M. (Orgs.). Exclusão social e mobilidade no Brasil. Brasília: Ipea, Banco Mundial, 2005, Cap.4, p.131-145.

MARTELETO, L. Family size, demographic change, and education attainment: the case of Brazil. Ann Arbor, MI: Population Studies Center, University of Michigan, 2005 (PSC research report, 05-584).

MCKAY, A.; LAWSON, D. Chronic poverty: a review of current quantitative evidence. Manchester: IDPM/Chronic Poverty Research Centre (CPRC), 2002 (Working paper, 15).

MEDEIROS, M.; OSÓRIO, R. Mudanças nas famílias brasileiras: a composição dos arranjos domiciliares entre 1978 e 1998. Brasília: Ipea, 2002 (Texto para discussão, 886).

OLIVEIRA, A. M. H. Acumulando informações e estudando mudanças ao longo do tempo: análises longitudinais do mercado de trabalho brasileiro. 2002. 138f. Tese (Doutorado em Demografia) - Centro de Desenvolvimento e Planejamento Regional, Universidade Federal de Minas Gerais. $2^{\mathrm{o}}$ Artigo: Tendências da desigualdade salarial para coortes de mulheres brancas e negras no Brasil, p.64-96.

PRESTON, S. H. Relations between individual life cycles and population characteristics. American Sociological Review, v.47, p.253-264, Apr. 1982.

RAVALLION, M. Expected poverty under riskinduced welfare variability. Economic Journal, v.98, p. 1171-1182, Dec. 1988.
RIBAS, R. P.; MACHADO, A. F. Distinguishing chronic poverty from transient poverty in Brazil: developing a model for pseudo-panel data. Brasilia: International Poverty Centre/ UNDP, 2007 (Working Paper, 36).

RIOS-NETO, E. L. G.; OLIVEIRA, A. M. H. Aplicação de um modelo de idade-períodocoorte para a atividade econômica no Brasil metropolitano. Pesquisa e Planejamento Econômico, v.29, n.2, p.243-272, 1999.

ROCHA, S. Pobreza no Brasil: afinal, de que se trata? Rio de Janeiro: FGV, 2003.

RODGERS, W. L. Estimable functions of age, period, and cohort effects. American Sociological Review, v.47, n.6, p.774-787, 1982.

RYDER, N. B. The cohort as a concept in the study of social change. American Sociological Review, v.30, n.6, p.843-861, 1965.

SILVA, F. A. R.; TAFNER, P. (Eds.). Brasil: o estado de uma nação. Rio de Janeiro: Ipea, 2005.

SILVA, P. L. N.; PESSOA, D. G. C.; LILA, M. F. Análise estatística de dados da PNAD: incorporando a estrutura do plano amostral. Ciência \& Saúde Coletiva, v.7, n.4, p.659670, 2002.

VELEZ, C. E.; SOARES, S.; MEDEIROS, M. Reducing schooling inequality in Brazil: demographic opportunities and inter-cohort differentials. Rio de Janeiro: Ipea, 2001 (Texto para discussão, 850).

VILLALOBOS, V. S. O estado de bem-estar social na América Latina: necessidade de redefinição. Caderno Adenauer 1: pobreza e política social. São Paulo: Fundação Konrad Adenauer, 2000, p.49-69.

WILMOTH, J. R. Age-period-cohort models in demography. In: CASELLI, G.; VALLIN, J.; WUNSCH, G. (Eds.). Démographie: analyse et synthèse, forthcoming, 1998. Disponível em: <http://demog.berkeley.edu/jrw/ Papers/apc.pdf $>$.

WOOD, G. Staying secure, staying poor: the "Faustian Bargain". World Development, v.31, n.3, p.455-471, 2003. 


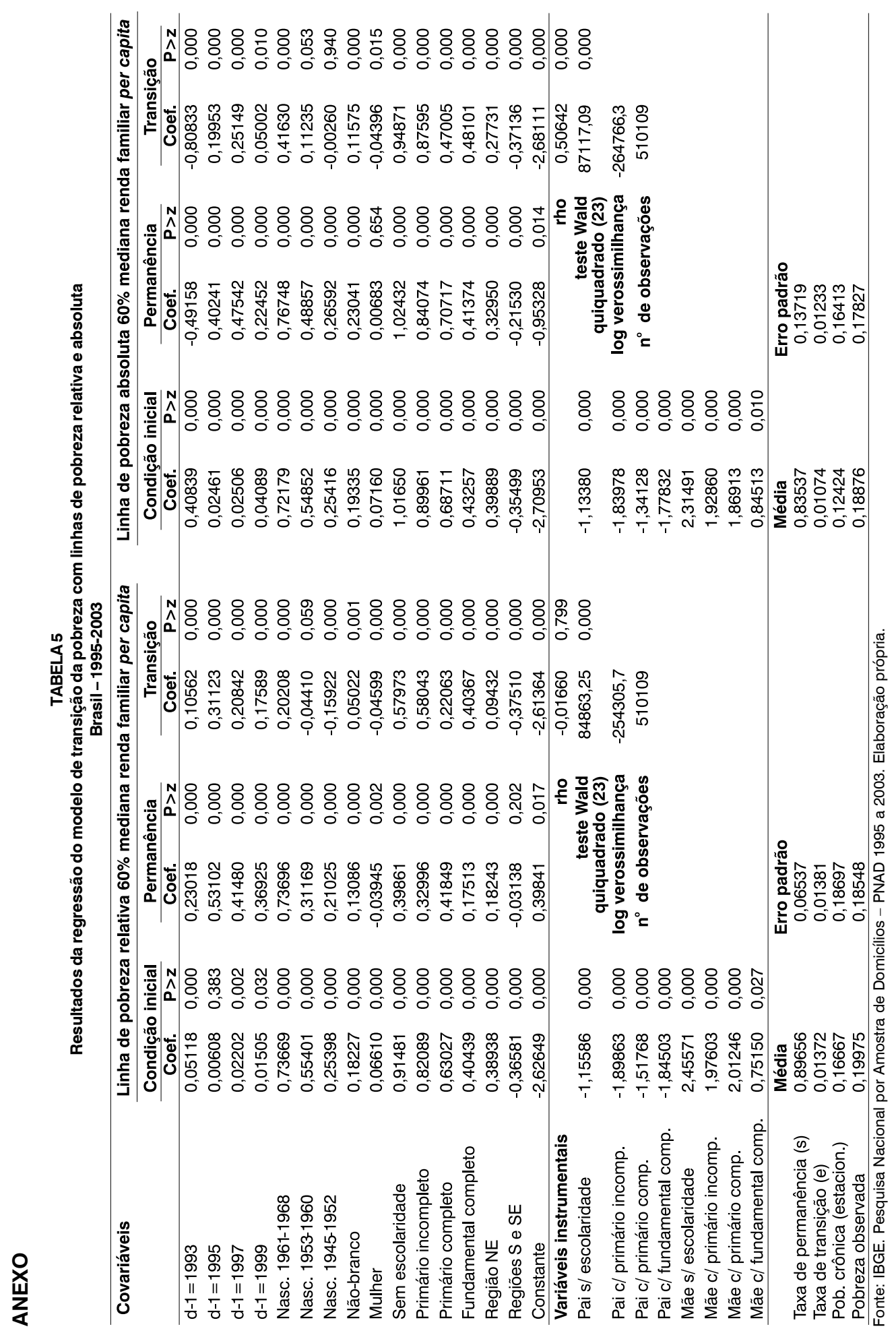


TABELA 6

Composição da amostra, segundo idade

Brasil - 1995-2003

\begin{tabular}{|c|c|c|c|c|c|c|}
\hline Idade & 1995 & 1997 & 1999 & 2001 & 2003 & Total \\
\hline $27-28$ anos & 0,0169 & & & & & 0,0169 \\
\hline $29-30$ anos & 0,0174 & 0,0171 & & & & 0,0346 \\
\hline 31-32 anos & 0,0170 & 0,0175 & 0,0169 & & & 0,0514 \\
\hline 33-34 anos & 0,0157 & 0,0172 & 0,0173 & 0,0187 & & 0,0690 \\
\hline $35-36$ anos & 0,0156 & 0,0158 & 0,0173 & 0,0189 & 0,0188 & 0,0864 \\
\hline 37-38 anos & 0,0150 & 0,0157 & 0,0159 & 0,0189 & 0,0190 & 0,0845 \\
\hline $39-40$ anos & 0,0144 & 0,0153 & 0,0158 & 0,0176 & 0,0188 & 0,0820 \\
\hline 41-42 anos & 0,0128 & 0,0140 & 0,0146 & 0,0169 & 0,0173 & 0,0756 \\
\hline 43-44 anos & 0,0118 & 0,0130 & 0,0138 & 0,0157 & 0,0169 & 0,0711 \\
\hline $45-46$ anos & 0,0112 & 0,0116 & 0,0128 & 0,0144 & 0,0158 & 0,0659 \\
\hline 47-48 anos & 0,0102 & 0,0111 & 0,0114 & 0,0136 & 0,0147 & 0,0611 \\
\hline 49-50 anos & 0,0089 & 0,0101 & 0,0111 & 0,0124 & 0,0141 & 0,0566 \\
\hline $51-52$ anos & 0,0080 & 0,0087 & 0,0096 & 0,0116 & 0,0122 & 0,0503 \\
\hline 53-54 anos & 0,0074 & 0,0079 & 0,0089 & 0,0103 & 0,0115 & 0,0460 \\
\hline 55-56 anos & 0,0075 & 0,0072 & 0,0077 & 0,0089 & 0,0105 & 0,0419 \\
\hline 57-58 anos & 0,0064 & 0,0071 & 0,0072 & 0,0080 & 0,0087 & 0,0374 \\
\hline $59-60$ anos & & 0,0063 & 0,0072 & 0,0074 & 0,0083 & 0,0292 \\
\hline $61-62$ anos & & & 0,0061 & 0,0073 & 0,0072 & 0,0205 \\
\hline 63-64 anos & & & & 0,0062 & 0,0075 & 0,0136 \\
\hline $65-66$ anos & & & & & 0,0062 & 0,0062 \\
\hline Total & 0,1964 & 0,1956 & 0,1937 & 0,2069 & 0,2074 & 1,0000 \\
\hline Número de estratos & & 2.219 & \multicolumn{3}{|c|}{ Número de observações } & 512.690 \\
\hline Número de UPAs & & 25.528 & \multicolumn{3}{|c|}{ Tamanho da população } & $2,31 E+08$ \\
\hline & & & \multicolumn{3}{|c|}{ Graus de liberdade } & 23.309 \\
\hline
\end{tabular}

Fonte: IBGE. Pesquisa Nacional por Amostra de Domicílios - PNAD 1995 a 2003. Elaboração própria.

TABELA 7

Resultados das regressões do modelo IPC de pobreza absoluta, com uso de dummies Brasil - 1995-2003

\begin{tabular}{|c|c|c|c|c|c|c|c|}
\hline \multirow{3}{*}{ Dummies } & \multicolumn{7}{|c|}{ Pobreza absoluta } \\
\hline & \multicolumn{3}{|c|}{ Total } & \multicolumn{3}{|c|}{ Crônica } & \multirow{2}{*}{$\begin{array}{c}\text { Transitória } \\
\text { ef. marg. }\end{array}$} \\
\hline & ef. marg. & coef. & $P>|t|$ & ef. marg. & coef. & $P>|t|$ & \\
\hline Idade $31-32$ & $-0,00388$ & $-0,02746$ & 0,595 & $-0,00021$ & $-0,00187$ & 0,942 & $-0,00367$ \\
\hline Idade 33-34 & $-0,00868$ & $-0,06207$ & 0,466 & $-0,00766$ & $-0,06953$ & 0,105 & $-0,00102$ \\
\hline Idade 35-36 & $-0,01562$ & $-0,11321$ & 0,348 & $-0,00750$ & $-0,06810$ & 0,259 & $-0,00811$ \\
\hline Idade $37-38$ & $-0,02583$ & $-0,19141$ & 0,219 & $-0,00564$ & $-0,05119$ & 0,513 & $-0,02019$ \\
\hline Idade $39-40$ & $-0,03573$ & $-0,27085$ & 0,160 & $-0,00388$ & $-0,03520$ & 0,716 & $-0,03185$ \\
\hline Idade $41-42$ & $-0,04866$ & $-0,38120$ & 0,096 & 0,03345 & 0,30366 & 0,008 & $-0,08211$ \\
\hline Idade $43-44$ & $-0,05895$ & $-0,47522$ & 0,074 & 0,01078 & 0,09790 & 0,463 & $-0,06973$ \\
\hline Idade $45-46$ & $-0,07809$ & $-0,66779$ & 0,027 & 0,01073 & 0,09741 & 0,521 & $-0,08882$ \\
\hline Idade $47-48$ & $-0,08562$ & $-0,75288$ & 0,026 & 0,01125 & 0,10210 & 0,548 & $-0,09687$ \\
\hline Idade $49-50$ & $-0,09298$ & $-0,84207$ & 0,025 & 0,01931 & 0,17530 & 0,352 & $-0,11228$ \\
\hline Idade 51-52 & $-0,10317$ & $-0,97806$ & 0,017 & 0,01172 & 0,10645 & 0,606 & $-0,11489$ \\
\hline
\end{tabular}




\begin{tabular}{|c|c|c|c|c|c|c|c|}
\hline \multirow{3}{*}{ Dummies } & \multicolumn{7}{|c|}{ Pobreza absoluta } \\
\hline & \multicolumn{3}{|c|}{ Total } & \multicolumn{3}{|c|}{ Crônica } & \multirow{2}{*}{$\begin{array}{c}\text { Transitória } \\
\text { ef. marg. }\end{array}$} \\
\hline & ef. marg. & coef. & $P>|t|$ & ef. marg. & coef. & $P>|t|$ & \\
\hline Idade 53-54 & $-0,10931$ & $-1,06935$ & 0,017 & 0,00894 & 0,08121 & 0,718 & $-0,11825$ \\
\hline Idade $55-56$ & $-0,11554$ & $-1,17009$ & 0,016 & 0,00382 & 0,03471 & 0,887 & $-0,11936$ \\
\hline Idade $57-58$ & $-0,12667$ & $-1,37081$ & 0,008 & $-0,00375$ & $-0,03408$ & 0,896 & $-0,12292$ \\
\hline Idade $59-60$ & $-0,13208$ & $-1,50218$ & 0,007 & $-0,01440$ & $-0,13071$ & 0,641 & $-0,11768$ \\
\hline Idade $61-62$ & $-0,13991$ & $-1,72255$ & 0,004 & $-0,01478$ & $-0,13417$ & 0,654 & $-0,12513$ \\
\hline Idade 63-64 & $-0,14765$ & $-2,00006$ & 0,002 & $-0,01561$ & $-0,14173$ & 0,656 & $-0,13204$ \\
\hline Idade $65-66$ & $-0,15156$ & $-2,22588$ & 0,001 & $-0,02084$ & $-0,18924$ & 0,574 & $-0,13071$ \\
\hline Ano 1995 & $-0,03530$ & $-0,26146$ & 0,073 & $-0,48103$ & $-4,36737$ & 0,000 & 0,44573 \\
\hline Ano 1997 & $-0,02886$ & $-0,21167$ & 0,066 & 0,13579 & 1,23288 & 0,000 & $-0,16465$ \\
\hline Ano 1999 & $-0,01573$ & $-0,11309$ & 0,142 & 0,16730 & 1,51898 & 0,000 & $-0,18303$ \\
\hline Ano 2001 & $-0,00680$ & $-0,04823$ & 0,266 & 0,04438 & 0,40297 & 0,000 & $-0,05118$ \\
\hline Coorte $1939-40$ & $-0,01133$ & $-0,08167$ & 0,122 & $-0,00843$ & $-0,07655$ & 0,002 & $-0,00290$ \\
\hline Coorte 1941-42 & $-0,02942$ & $-0,22148$ & 0,008 & $-0,02375$ & $-0,21565$ & 0,000 & $-0,00567$ \\
\hline Coorte $1943-44$ & $-0,04501$ & $-0,35281$ & 0,003 & $-0,03227$ & $-0,29303$ & 0,000 & $-0,01274$ \\
\hline Coorte 1945-46 & $-0,06102$ & $-0,50028$ & 0,001 & $-0,04093$ & $-0,37165$ & 0,000 & $-0,02008$ \\
\hline Coorte 1947-48 & $-0,06974$ & $-0,58574$ & 0,002 & $-0,04936$ & $-0,44814$ & 0,000 & $-0,02039$ \\
\hline Coorte 1949-50 & $-0,07798$ & $-0,67029$ & 0,003 & $-0,05523$ & $-0,50146$ & 0,000 & $-0,02275$ \\
\hline Coorte 1951-52 & $-0,08381$ & $-0,73322$ & 0,005 & $-0,06288$ & $-0,57086$ & 0,000 & $-0,02093$ \\
\hline Coorte 1953-54 & $-0,09217$ & $-0,82569$ & 0,005 & $-0,06606$ & $-0,59977$ & 0,000 & $-0,02611$ \\
\hline Coorte 1955-56 & $-0,09871$ & $-0,90134$ & 0,006 & $-0,03580$ & $-0,32505$ & 0,053 & $-0,06291$ \\
\hline Coorte 1957-58 & $-0,10105$ & $-0,92605$ & 0,012 & $-0,03421$ & $-0,31057$ & 0,095 & $-0,06684$ \\
\hline Coorte $1959-60$ & $-0,10390$ & $-0,95796$ & 0,018 & $-0,03330$ & $-0,30235$ & 0,139 & $-0,07060$ \\
\hline Coorte 1961-62 & $-0,10280$ & $-0,94280$ & 0,032 & $-0,00148$ & $-0,01344$ & 0,952 & $-0,10132$ \\
\hline Coorte $1963-64$ & $-0,10591$ & $-0,97538$ & 0,041 & 0,12086 & 1,09735 & 0,000 & $-0,22678$ \\
\hline Coorte 1965-66 & $-0,10587$ & $-0,97407$ & 0,058 & 0,11950 & 1,08495 & 0,000 & $-0,22537$ \\
\hline Coorte 1967-68 & $-0,10740$ & $-0,99499$ & 0,068 & 0,11960 & 1,08592 & 0,000 & $-0,22700$ \\
\hline Constante & & $-0,10933$ & 0,870 & & $-3,36957$ & 0,000 & \\
\hline $\begin{array}{l}\text { Número de } \\
\text { observações }\end{array}$ & 512.690 & & & 512.690 & & & \\
\hline Número de estratos & 2.219 & & & 2.219 & & & \\
\hline Número de PSUs & 25.528 & & & 25.528 & & & \\
\hline $\begin{array}{l}\text { Tamanho da } \\
\text { população }\end{array}$ & $2,31 E+08$ & & & $2,31 E+08$ & & & \\
\hline Graus de liberdade & 23.309 & & & 23.309 & & & \\
\hline$F(37,23273)$ & 61,49 & & & 4974,95 & & & \\
\hline Prob $>\mathrm{F}$ & 0,0000 & & & 0,0000 & & & \\
\hline
\end{tabular}

Fonte: IBGE. Pesquisa Nacional por Amostra de Domicílios - PNAD 1995 a 2003. Elaboração própria.

TABELA 8

Resultados das regressões do modelo IPC de pobreza relativa, com uso de dummies Brasil - 1995-2003

\begin{tabular}{|c|c|c|c|c|c|c|c|}
\hline \multirow{3}{*}{ Dummies } & \multicolumn{7}{|c|}{ Pobreza relativa } \\
\hline & \multicolumn{3}{|c|}{ Total } & \multicolumn{3}{|c|}{ Crônica } & \multirow{2}{*}{$\begin{array}{r}\text { Transitória } \\
\text { ef. marg. }\end{array}$} \\
\hline & ef. marg. & coef. & $P>|t|$ & ef. marg. & coef. & $P>|t|$ & \\
\hline Idade 31-32 & $-0,00483$ & $-0,03280$ & 0,521 & $-0,00273$ & $-0,01927$ & 0,470 & $-0,00211$ \\
\hline Idade 33-34 & $-0,01101$ & $-0,07552$ & 0,371 & $-0,01194$ & $-0,08437$ & 0,056 & 0,00094 \\
\hline Idade $35-36$ & $-0,02014$ & $-0,14052$ & 0,239 & $-0,01742$ & $-0,12304$ & 0,048 & $-0,00272$ \\
\hline Idade 37-38 & $-0,03181$ & $-0,22724$ & 0,140 & $-0,01897$ & $-0,13401$ & 0,096 & $-0,01283$ \\
\hline
\end{tabular}


(continuação)

\begin{tabular}{|c|c|c|c|c|c|c|c|}
\hline \multirow{3}{*}{ Dummies } & \multicolumn{7}{|c|}{ Pobreza relativa } \\
\hline & \multicolumn{3}{|c|}{ Total } & \multicolumn{3}{|c|}{ Crônica } & \multirow{2}{*}{$\begin{array}{r}\text { Transitória } \\
\text { ef. marg. }\end{array}$} \\
\hline & ef. marg. & coef. & $P>|t|$ & ef. marg. & coef. & $P>|t|$ & \\
\hline Idade $39-40$ & $-0,04330$ & $-0,31719$ & 0,096 & $-0,02069$ & $-0,14610$ & 0,142 & $-0,02261$ \\
\hline Idade 41-42 & $-0,05733$ & $-0,43477$ & 0,055 & 0,02775 & 0,19601 & 0,098 & $-0,08509$ \\
\hline Idade 43-44 & $-0,06891$ & $-0,53916$ & 0,040 & $-0,00691$ & $-0,04880$ & 0,722 & $-0,06200$ \\
\hline Idade $45-46$ & $-0,08807$ & $-0,72988$ & 0,015 & $-0,00787$ & $-0,05558$ & 0,722 & $-0,08020$ \\
\hline Idade $47-48$ & $-0,09694$ & $-0,82949$ & 0,013 & $-0,00765$ & $-0,05400$ & 0,758 & $-0,08930$ \\
\hline Idade $49-50$ & $-0,10509$ & $-0,92872$ & 0,012 & 0,00822 & 0,05803 & 0,765 & $-0,11331$ \\
\hline Idade 51-52 & $-0,11585$ & $-1,07437$ & 0,008 & $-0,01060$ & $-0,07485$ & 0,725 & $-0,10525$ \\
\hline Idade 53-54 & $-0,12254$ & $-1,17602$ & 0,008 & $-0,01246$ & $-0,08803$ & 0,703 & $-0,11008$ \\
\hline Idade 55-56 & $-0,12817$ & $-1,27051$ & 0,008 & $-0,01494$ & $-0,10552$ & 0,673 & $-0,11322$ \\
\hline Idade $57-58$ & $-0,13864$ & $-1,46428$ & 0,004 & $-0,01959$ & $-0,13837$ & 0,607 & $-0,11905$ \\
\hline Idade $59-60$ & $-0,14397$ & $-1,59945$ & 0,004 & $-0,02202$ & $-0,15556$ & 0,590 & $-0,12195$ \\
\hline Idade $61-62$ & $-0,15080$ & $-1,80282$ & 0,002 & $-0,01953$ & $-0,13792$ & 0,654 & $-0,13127$ \\
\hline Idade $63-64$ & $-0,15767$ & $-2,05686$ & 0,001 & $-0,02075$ & $-0,14654$ & 0,654 & $-0,13692$ \\
\hline Idade $65-66$ & $-0,16023$ & $-2,22808$ & 0,001 & $-0,02257$ & $-0,15944$ & 0,645 & $-0,13765$ \\
\hline Ano 1995 & $-0,04273$ & $-0,30481$ & 0,035 & 0,07758 & 0,54799 & 0,000 & $-0,12032$ \\
\hline Ano 1997 & $-0,03192$ & $-0,22411$ & 0,049 & 0,23404 & 1,65304 & 0,000 & $-0,26595$ \\
\hline Ano 1999 & $-0,02174$ & $-0,15053$ & 0,048 & 0,16180 & 1,14284 & 0,000 & $-0,18355$ \\
\hline Ano 2001 & $-0,00639$ & $-0,04330$ & 0,312 & 0,14087 & 0,99501 & 0,000 & $-0,14726$ \\
\hline Coorte 1939-40 & $-0,00882$ & $-0,06038$ & 0,245 & $-0,00520$ & $-0,03673$ & 0,127 & $-0,00362$ \\
\hline Coorte 1941-42 & $-0,02759$ & $-0,19672$ & 0,017 & $-0,01900$ & $-0,13423$ & 0,001 & $-0,00859$ \\
\hline Coorte 1943-44 & $-0,04511$ & $-0,33534$ & 0,004 & $-0,02448$ & $-0,17294$ & 0,004 & $-0,02063$ \\
\hline Coorte $1945-46$ & $-0,06189$ & $-0,48040$ & 0,001 & $-0,05451$ & $-0,38504$ & 0,000 & $-0,00738$ \\
\hline Coorte $1947-48$ & $-0,07239$ & $-0,57739$ & 0,002 & $-0,06383$ & $-0,45085$ & 0,000 & $-0,00856$ \\
\hline Coorte 1949-50 & $-0,08247$ & $-0,67568$ & 0,002 & $-0,07091$ & $-0,50088$ & 0,000 & $-0,01155$ \\
\hline Coorte 1951-52 & $-0,08931$ & $-0,74623$ & 0,004 & $-0,08098$ & $-0,57194$ & 0,000 & $-0,00833$ \\
\hline Coorte 1953-54 & $-0,09851$ & $-0,84377$ & 0,004 & $-0,08199$ & $-0,57909$ & 0,000 & $-0,01653$ \\
\hline Coorte 1955-56 & $-0,10611$ & $-0,92838$ & 0,005 & $-0,02324$ & $-0,16414$ & 0,340 & $-0,08287$ \\
\hline Coorte 1957-58 & $-0,10937$ & $-0,96299$ & 0,008 & $-0,02321$ & $-0,16394$ & 0,390 & $-0,08616$ \\
\hline Coorte 1959-60 & $-0,11305$ & $-1,00354$ & 0,012 & $-0,02496$ & $-0,17627$ & 0,400 & $-0,08809$ \\
\hline Coorte 1961-62 & $-0,11276$ & $-0,99850$ & 0,022 & 0,01696 & 0,11976 & 0,600 & $-0,12971$ \\
\hline Coorte 1963-64 & $-0,11700$ & $-1,04352$ & 0,027 & 0,19341 & 1,36611 & 0,000 & $-0,31041$ \\
\hline Coorte 1965-66 & $-0,11739$ & $-1,04756$ & 0,039 & 0,18875 & 1,33319 & 0,000 & $-0,30614$ \\
\hline Coorte 1967-68 & $-0,11966$ & $-1,07793$ & 0,046 & 0,18693 & 1,32034 & 0,000 & $-0,30659$ \\
\hline Constante & & 0,06415 & 0,922 & & $-3,39463$ & 0,000 & \\
\hline $\begin{array}{l}\text { Número de } \\
\text { observações }\end{array}$ & 512.690 & & & 512.690 & & & \\
\hline Número de estratos & 2.219 & & & 2.219 & & & \\
\hline Número de PSUs & 25.528 & & & 25.528 & & & \\
\hline $\begin{array}{l}\text { Tamanho da } \\
\text { população }\end{array}$ & $2.31 E+08$ & & & $2.31 \mathrm{E}+08$ & & & \\
\hline Graus de liberdade & 23.309 & & & 23.309 & & & \\
\hline$F(37,23273)$ & 61,23 & & & 3038,76 & & & \\
\hline Prob $>F$ & 0,0000 & & & 0,0000 & & & \\
\hline
\end{tabular}

Fonte IBGE. Pesquisa Nacional por Amostra de Domicílios - PNAD 1995 a 2003. Elaboração própria. 


\section{Resumen}

La caracterización de la pobreza urbana a lo largo del tiempo: aplicación del modelo edadperíodo-cohorte en la estimación de las tendencias de privaciones crónica y transitoria en Brasil

A lo largo de las últimas décadas, la pobreza en Brasil viene cambiando su perfil, debido, en parte, a modificaciones en el padrón de reproducción y mortalidad de la población. De la misma forma, los diseños de políticas sociales, especialmente de combate a la pobreza, tomaron otros rumbos. En este aspecto, la pertinencia de esos nuevos diseños depende de la naturaleza de la condición de baja renta, pudiendo ser entendida como un fenómeno permanente o temporal y, principalmente, de la tendencia de cambios en esa composición transitoria-crónica (T-C). El objetivo de este trabajo es justamente analizar esa tendencia, así como el proceso de incidencia de la pobreza urbana, en términos de modificaciones a lo largo del tiempo y de generaciones de individuos, proyectando medidas futuras de privación en la renta. Para ello es utilizado un modelo de edad-período-cohorte (IPC) sobre la pobreza, absoluta y relativa, observada en las PNADs entre 1995 y 2003, y sobre su composición T-C estimada. Los resultados apuntan que el efecto cohorte es más indicativo que el de período sobre la reducción de la pobreza recientemente, en especial de su componente crónico. Ya el componente transitorio presenta tendencia de aumento a lo largo del tiempo.

Palabras-clave: Pobreza crónica y transitoria. Modelo edad-período-cohorte (IPC). Proyección de pobreza.

\section{Abstract \\ Characterizing urban poverty over time: The use of the Age-Period-Cohort model for estimating chronic and transient poverty trends in Brazil}

The profile of poverty in Brazil has changed in recent decades, partially due to alterations in the reproduction and mortality standards of the population. During this same period, the designs of social policies, especially those for reducing poverty, have also undergone changes. It must be emphasized that the effectiveness of these policies depends on the type of poverty that is being dealt with. Destitution can be a permanent or temporary phenomenon, and this transient-chronic (T-C) composition may show a temporal trend. The objective of this paper is to analyze this trend as well as the temporal evolution of poverty rates in urban areas. The result may make it possible to predict future income and destitution. To this end, an Age-Period-Cohort (APC) model was applied to absolute and relative poverty measures and to the T-C composition, based on data from the PNADs between 1995 and 2003. The results indicate that the cohort-effect is more expressive than the period effect for the recent reduction in poverty rates, especially for the chronic component. In contrast, the transient component showed a relative temporal tendency to increase.

Keywords: Chronic Poverty and Transient Poverty; Age-Period-Cohort (APC) Model; Prediction of Poverty

Recebido para publicação em 14/12/2006. Aceito para publicação em 31/05/2007. 
